\title{
Postendodontic Pain after Pulpotomy or Root Canal Treatment in Mature Teeth with Carious Pulp Exposure: A Multicenter Randomized Controlled Trial
}

\author{
Mohammad Jafar Eghbal (D), ${ }^{1}$ Ali Haeri, ${ }^{1}$ Arash Shahravan $\left(D,{ }^{2}\right.$ Ali Kazemi, ${ }^{3}$ \\ Fariborz Moazami $\mathbb{D}$, ${ }^{4}$ Mohammad Ali Mozayeni $\mathbb{D}^{5}{ }^{5}$ Eshaghali Saberi, ${ }^{6}$ \\ Mohammad Samiei, ${ }^{7}$ Mehdi Vatanpour ${ }^{(D)},{ }^{8}$ Alireza Akbarzade Baghban ${ }^{(D)}, 9$ \\ Mahta Fazlyab ${ }^{D},{ }^{8}$ Ardavan Parhizkar $\left(D,{ }^{1}\right.$ Mahboobe Ahmadi $(D),{ }^{6}$ Nazila Akbarian Rad, ${ }^{5}$ \\ Shima Bijari (D), ${ }^{6}$ Delaram Bineshmarvasti $\left(\mathbb{D},{ }^{8}\right.$ Paria Davoudi $\left(\mathbb{D},{ }^{7}\right.$ Roya Dehghan $\left(\mathbb{D},{ }^{4}\right.$ \\ Mandana Dehghani ${ }^{D},{ }^{4}$ Habibollah Ebrahimi, ${ }^{6}$ Nafiseh Emami ${ }^{8},{ }^{8}$ Nafiseh Farajian, ${ }^{3}$ \\ Rahim Fereidooni (iD, ${ }^{2}$ Gelareh Ghobadi, ${ }^{8}$ Mostafa Ghodrati ${ }^{1}{ }^{7}$ Atefeh Gohari $\left(\mathbb{D},{ }^{5}\right.$ \\ Azadeh Hashemi (iD, ${ }^{2}$ Mohammadreza Hosseini, ${ }^{5}$ Elham Karami (iD), ${ }^{4}$ Nasir Kheirabadi (D), \\ Sepideh Kozegari, ${ }^{7}$ Hadi Labaf Ghasemi, ${ }^{8}$ Alireza Majidi, ${ }^{7}$ Parastu Malekzadeh, ${ }^{4}$ \\ Vahid Mehrabi, ${ }^{4}$ Mehrnush Mohammadi ${ }^{1}{ }^{7}$ Leila Moradi Eslami, ${ }^{8}$ Atefeh Noghani, ${ }^{7}$ \\ Negin Omatali $\left(\mathbb{D},{ }^{8}\right.$ Negar Pourhatami $\mathbb{D}^{4},{ }^{4}$ Behnam Rahbani Nobar $\mathbb{D}^{5},{ }^{5}$ Saeid Rahmani ${ }^{2},{ }^{2}$ \\ Parviz Shafaq, ${ }^{5}$ Sara Soofiabadi, ${ }^{2}$ Somaye Teimoori, ${ }^{3}$ Farzaneh Vatandoost ${ }^{(D,}{ }^{5}$ \\ and Saeed Asgary iD $^{1}$
}

${ }^{1}$ Iranian Center for Endodontic Research, Research Institute for Dental Sciences, Shahid Beheshti University of Medical Sciences, Tehran 1983963113, Iran

${ }^{2}$ Endodontology Research Center, Endodontic Department, Dental School, Kerman University of Medical Sciences, Kerman 7618751689, Iran

${ }^{3}$ Endodontic Department, Dental School, Shahed University, Tehran 1417755351, Iran

${ }^{4}$ Endodontic Department, Dental School, Shiraz University of Medical Science, Shiraz 7134814336, Iran

${ }^{5}$ Endodontic Department, Dental School, Shahid Beheshti University of Medical Sciences, Tehran 1983963113, Iran

${ }^{6}$ Endodontic Department, Oral and Dental Diseases Research Center, Dental School, Zahedan University of Medical Sciences, Zahedan 9816743463, Iran

${ }^{7}$ Endodontic Department, Dental School, Tabriz University of Medical Sciences, Tabriz 5166614713, Iran

${ }^{8}$ Endodontic Department, Dental Branch, Islamic Azad University, Tehran 1946853314, Iran

${ }^{9}$ Department of Basic Sciences, Proteomics Research Center, School of Rehabilitation,

Shahid Beheshti University of Medical Sciences, Tehran 1616913111, Iran

Correspondence should be addressed to Saeed Asgary; saasgary@yahoo.com

Received 26 August 2019; Revised 13 April 2020; Accepted 6 May 2020; Published 30 June 2020

Academic Editor: Shinya Kasai

Copyright (C) 2020 Mohammad Jafar Eghbal et al. This is an open access article distributed under the Creative Commons Attribution License, which permits unrestricted use, distribution, and reproduction in any medium, provided the original work is properly cited.

This equivalence, randomized, clinical trial aimed to compare the postoperative pain of root canal therapy (RCT) with pulpotomy with mineral trioxide aggregate (PMTA) or calcium-enriched mixture (PCEM) in permanent mature teeth. In seven academic centers, 550 cariously exposed pulps were included and randomly allocated into PMTA $(n=188)$, PCEM $(n=194)$, or RCT $(n=168)$ arms. Preoperative "Pain Intensity" (PI) on Numerical Rating Scale and postoperative PIs until day 7 were recorded. Patients' demographic and pre-/intra-/postoperative factors/conditions were recorded/analysed. The arms were homogeneous in terms of demographics. The mean preoperative PIs were similar $(P=0.998)$, the mean sum PIs recorded during 10 postoperative 
intervals were comparable $(P=0.939)$, and the trend/changes in pain relief were parallel $(P=0.821)$ in all study arms. The incidences of preoperative moderate-severe pain in RCT, PMTA, and PCEM arms were 56.5\%, 55.7\%, and 56.7\%, which after 24 hours considerably decreased to $13.1 \%, 10.6 \%$, and $12.9 \%$, respectively $(P=0.578)$. The time span of endodontic procedures was statistically different; RCT $=69.73, \mathrm{PMTA}=35.37$, and $\mathrm{PCEM}=33.62$ minutes $(P<0.001)$. Patients with greater preoperative pain, symptomatic apical periodontitis, or presence of PDL widening suffered more pain $(P=0.002,0.035$, and 0.023 , resp.); however, other pre-/intra-/postoperative factors/conditions were comparable. Pulpotomy with MTA/CEM and RCT demonstrate comparable and effective postoperative pain relief.

\section{Introduction}

Dental caries, as a chronic infectious disease, is a global health concern. The untreated caries is the most prevalent condition (global prevalence $=34.1 \%$ ) evaluated for the entire "Global Burden of Disease", as it remains the main cause for loss of all teeth [1]. Endodontic diseases, as the sequelae of untreated caries, affect oral health-related quality of life with moderate severity, mainly through physical pain of pulpitis [2]. A systematic review showed that the mean prevalence of preoperative endodontic-associated pain was as high as $81 \%$ [3]. Therefore, endodontic pain can considerably affect the quality of life. In addition, endodontic pain was the most prevalent self-reported reason for tooth extraction [4].

Pain research has gradually expanded its prominence in all medical- and dental-related sciences. In endodontology, pain control in intra- and postoperative phases is a key aspect of clinical practice. Despite novel advancements in endodontology, up to $58 \%$ of patients have experienced postendodontic pain [5]. The postoperative endodontic pain is a multifactorial phenomenon. Previous researches have tried to correlate it with predictive factors such as the patient- and tooth-related determinants as well as pre- and intraoperative conditions $[3,6,7]$. However, results have often been uncertain, unpredictable, or lacking obvious "cause and effect" relationship [2].

The single available Cochrane review, appraising pulp management in carious permanent mature teeth with inflamed pulp, was not able to reach a conclusion and thus stated that further well-designed randomized controlled trials would be compulsory [8]. Recently, endodontology has focused on biologically based restorative solutions [9] for the management of extremely deep caries, so that it could preserve pulpal vitality/health and the integrity of tooth structure with minimally invasive approaches for instance vital pulp therapy (VPT) [10]. According to the "European Society of Endodontology (ESE) position statement" in extremely deep caries lesion, the caries entering the entire thickness of the dentine and the pulp exposure is unavoidable during operative treatment [11]. In carious pulp exposures, if inflammation/infection is effectively controlled, VPT, employing endodontic biomaterials, can provide a biological seal against bacterial microleakage and promote the noninflamed pulp to create dentine-like hard tissue $[12,13]$. Unlike RCT, VPTs are not complex, lengthy, and costly; however, like RCT, they are successful, acceptable, accessible, and available [14]. Given the growing evidence supporting the clinical effectiveness of VPT, RCT is no longer the treatment of choice for the management of carious pulp exposures, although it may still be the routine practice. Furthermore, the advantages of VPT over RCT are not only the preservation of tooth structure but also the maintenance of pulp's mechanoreceptors, regeneration capacity, and proprioceptive feedback [15].

An ideal endodontic biomaterial for VPT must be biocompatible and antibacterial, able to provide a biological and bacterial-tight seal, and promote the regeneration of dentine-pulp complex [16]. Mineral trioxide aggregate (MTA) and calcium-enriched mixture (CEM) cement are two bioactive endodontic cements (BECs) with different chemical compositions [17] which are mainly comprised of calcium and silicate elements. MTA and CEM cement demonstrated similar antibacterial effect [18] and comparable sealing ability [19]. In terms of bioactivity and biocompatibility, these BECs are able to induce hard tissue formation, i.e., osteogenesis [20], dentinogenesis [21], and cementogenesis [22]. Based on such favorable properties, they are employed for VPTs with promising results [23].

A large noninferiority open-labelled clinical trial revealed that when general dentists treated cases with irreversible pulpitis, the pain-reducing effect of CEM pulpotomy (PCEM) was considerably more than that of RCT using hand instrumentation techniques [24]. Moreover, a recent randomized controlled trial reported that, in managing symptomatic permanent teeth with extremely deep caries lesions, in comparison with RCT, MTA pulpotomy (PMTA) effectively reduced postoperative endodontic pain [25]. A quadruple blinded randomized controlled trial also showed the comparable pain relief effect of PMTA and PCEM [26]. Another randomized clinical trial showed that the levels and incidence of postoperative endodontic pain were lesser in rotary instrumentation groups compared with manual preparation groups [27]. Hence, the aim of this randomized controlled trial was to compare the pain reduction of CEM or MTA pulpotomy with RCT using rotary instrumentation techniques; when postgraduate endodontic students managed extremely deep caries of mature permanent molars with/without clinical signs of irreversible pulpitis and apical periodontitis. The null hypothesis was, in terms of postoperative endodontic pain relief, PMTA/PCEM would be equivalent to RCT.

\section{Materials and Methods}

The Iranian Ministry of Health and Medical Education (IMHME) commissioned this project. The trial has been managed by the Iranian Center for Endodontic Research 
(ICER) and Research Institute for Dental Sciences (RIDS) of Shahid Beheshti University of Medical Sciences (SBMU), Tehran, Iran. The project was registered in the Iranian Registry of Clinical Trials (Registration Number IRCT20151226025695N3 and Registration Time 06 Feb., 2019) and approved by the Ethics Committee of Research Institute for Dental Sciences (IR.SBMU.RIDS.REC.1395.320) and Shahid Beheshti University of Medical Sciences (IR.SBMU.RETECH.REC.1397.1187). All experimental protocols were approved by RIDS (29-1395/ 09/23) and SBMU (10466-1396/04/26).

The trial was conducted in accordance with the ethical principles of the "Declaration of Helsinki" and "General Ethics Guideline" in Medical Sciences Research (which has a human subject) in Iran.

2.1. Resources. The research grant was funded by the Deputy Minister of Research, IMHME. The funder had no role in the design/conduct of the trial and analysis of the data.

2.2. Design of the Study. The project was a multicenter, randomized, open-label, clinical trial.

2.3. Hypothesis. For this part, we hypothesised that pulpotomy with endodontic biomaterials (MTA or CEM cement) would be considered as an equivalent to root canal therapy, employing rotary instrumentation, in terms of postoperative pain relief.

2.4. Objective. In this phase of the study, the primary outcome was to assess whether full pulpotomies with MTA or CEM cement decreased postoperative pain in permanent mature teeth with cariously exposed pulp compared with RCT.

Secondary outcomes were to assess probable associations between the following determinants and pain relief in cariously exposed mature teeth:

Patients' demographics (i.e., age, gender, level of education, and marital status)

Preoperative factors (i.e., baseline pain intensity/dental characteristics and pulp/periapical response to diagnostic tests/diagnosis)

Intraoperative factors (i.e., type of pulp exposure, type of pulpal hemorrhage with/without chlorhexidine/ $\mathrm{NaOCl}$, number of treatment sessions, and time-length of endodontic/restorative procedures)

Postoperative factors (pulp/periapical response to diagnostic tests and type/number of prescribed analgesics)

It should be noted that the main endpoint of the second phase of trial would be the two-year radiographic outcomes.

2.5. Criteria for Patient Selection. Volunteers were recruited from the pool of referred patients to seven postgraduate "Departments of Endodontics" in Iran. All patients had to adhere to inclusion and exclusion criteria.
2.6. Inclusion Criteria. Inclusion criteria were the following:

Vital molar teeth (confirmed with cold spray or electric pulp tester before treatment and visual inspection of pulpal hemorrhage after access cavity preparation)

A history of pain, indicating irreversible pulpitis (i.e., spontaneous localized/generalized pain, pain stimulated by hot/cold fluids that lasts after elimination of the stimulus and is reproducible with cold sensibility testing)

Pulp exposure during caries removal (when no clinical sign of irreversible pulpitis was present)

Patients in the range of 12 to 65 years of age

Patients who accepted to be available for recalls

Patients who approved and signed the written informed consent.

2.7. Exclusion Criteria. Exclusion criteria were the following:

Nonvital/partially necrotic teeth (confirmed with primary examinations or diagnosed after access cavity preparation)

Teeth with continuous bleeding (after placement of a cotton pellet soaked in sodium hypochlorite for a maximum of 10 minutes)

Teeth that were not appropriate candidates for class I or II restorations and required complicated build-ups, crown lengthening, or prosthetic crowns

Teeth with localized/generalized periodontal diseases (i.e., depth of probing ?3 mm)

Internal/external root resorption or detectable pulp chamber/canal calcification

Teeth with history of trauma

Immature teeth with open apices

Patients with systemic conditions that disturbed tissue healing process (i.e., diabetes, cancer, AIDS, intake of corticosteroids, and so forth)

Pregnant/nursing women

Physically/mentally disabled patients

Patients with poor oral hygiene

Immigrants, who were likely to leave the country during the subsequent two years

Patients younger than 12 years of age for the first molar treatment, 17 years of age for second molar treatment, and older than 65 years of age.

2.8. Informed Consent. Informed consent was obtained from all participants and from parents/legal guardians for patients under the age of 18 years.

2.9. Randomization. Patients were allocated in the three study arms with simple randomisation. Randomisation was performed online (http://www.mcrct.ir) immediately before the commencement of the treatment. After recording the 
patient's demographics, eligible patients, using a computergenerated system and under the supervision of administrative staff, were automatically randomised into different study arms including PMTA, PCEM, and RCT. All the allocated patients received a unique patient identification code before starting the treatment. In the event of withdrawal from the study, the randomisation code was not reused. Patient blinding was not implemented; however, the assessors and analysers were blinded.

\subsection{Treatments}

2.10.1. PMTA/PCEM. Each patient used a $0.2 \%$ chlorhexidine mouth rinse (Iran Najo Pharmaceutical Co., Tehran, Iran). Then, the teeth were anaesthetized with $2 \%$ lidocaine and 1:80000 epinephrine (Darou Pakhsh, Tehran, Iran). Upper and lower teeth were anaesthetized using infiltration and inferior alveolar nerve block techniques, respectively. Afterwards, cavity preparation and soft dentine removal were carried out using appropriate sterile high-speed diamond and low-speed large round burs, respectively. Subsequently, the tooth was isolated using a rubber dam and disinfected with $0.2 \%$ chlorhexidine.

Complete pulpotomy was performed by means of a new sterile long cylindrical round-ended diamond bur (Tiz Kavan, Tehran, Iran) in a high-speed handpiece with copious water irrigation. To achieve hemostasis, a cotton pellet moistened with $0.2 \%$ chlorhexidine was placed into the pulp chamber for $5 \mathrm{~min}$; and, if needed, it was replaced with a cotton pellet moistened with $\mathrm{NaOCl} 5.25 \%$ for $30 \mathrm{sec}$, or in cases of excessive hemorrhage, for 10 minutes. The pulpcovering agent (MTA, ProRoot, Dentsply, OK, USA, or CEM cement, Bionique Dent, Tehran, Iran) was prepared according to the manufacturer's instructions and then inserted into the pulp chamber. Using a dry sterile cotton pellet, the biomaterial was gently adapted on the blood clotfree pulpal wound and dentinal walls with a thickness of approximately $2-3 \mathrm{~mm}$. Within the same session (after the placement of a moistened cotton pellet for $5 \mathrm{~min}$ ) or further appointments, the cavity was permanently filled with Glass Ionomer (ChemFil, Dentsply, Konstanz, Germany) and light-cured resin-bonded dental composite (Filtek flowable/ Z250/Z350, 3M, ESPE, USA), employing open/close sandwich technique.

2.10.2. RCT. Similar to two other arms, teeth were anaesthetized and isolated, and pulpotomy was conducted. Then, working lengths were determined using Root ZX apex locator (J. Morita, Irvine, CA) and established $1 \mathrm{~mm}$ short of the apex employing parallel technique (X-ray Holder, Kerr Corporation, Orange, CA, USA). A digital radiograph confirmed the working lengths.

Root canal preparation was carried out using BioRaCe instruments (FKG Dentaire, La Chaux-de-Fonds, Switzerland). The endodontic motor (Endo-Mate TC, NSK, Nakanishi Inc., Tokyo, Japan) was adjusted at $600 \mathrm{rpm}$ and 1.5 $\mathrm{Ncm}$. Rotary files, with recommended sequences/motions, were employed in a crown-down manner according to the manufacturer's instructions. Root canals were irrigated with copious amounts of $5.25 \% \mathrm{NaOCl}$. Canal patency was confirmed with a \#10 K-file during the procedures. Master apical file usually ranged to BR4 (35/0.04) or BR5 (40/0.04) for straight canals or BR4C (35/0.02) for curved canals. After radiographic confirmation of master cone, the canals were dried with sterile paper points (Ariadent, Tehran, Iran). Using cold lateral condensation technique, root canals were filled/ sealed with multiple gutta-percha cones (Ariadent, Tehran, Iran) and AH-26 resin-based sealer (Dentsply, Tulsa Dental, Tulsa, OK, USA). Within the same/further sessions, the cavity was permanently filled employing sandwich technique.

2.11. Sample Size Calculation. Sample size was calculated based on the two-year outcomes in previous studies [28, 29]; the two-year radiographic success rates of PMTA, PCEM, and RCT were approximately 94\%, 86\%, and 80\%, respectively. Using PASS 11 software, considering the effect size $=0.168, \alpha=0.05$, and $\beta=0.1$ (power $=90 \%$ ), the estimated sample size was 449 .

2.12. Role of Participating Centers. Postgraduate departments of endodontics in seven universities of medical sciences, located in five states of Iran, collaborated in this multigroup collaboration. Thirty-four postgraduate students (PGS) with similar experience/skills participated in the study. The selected PGSs attended a training workshop at ICER, which included the demonstration of the study protocol, hands-on training in RCT, and protocols on full pulpotomy treatment. Then, PGSs took/passed the final test and were considered qualified for the trial. The primary task of each PGS was to recruit nine patients and fulfill including/ excluding criteria in each study arm. One endodontist from the academic staff of each department agreed to supervise all processes and activities, i.e., accordance of including/excluding criteria, standardisation of treatment, assessment of the outcomes, and recording of the data. The included centers were Azad Tehran $(P G S=6)$, Kerman $(P G S=5)$, Shahed $(P G S=2)$, Shahid Beheshti $(P G S=6)$, Shiraz $(P G S=6)$, Tabriz $(P G S=6)$, and Zahedan $(P G S=3)$ schools of dentistry.

2.13. Data Recording. Similar to previous studies [24], using a published pain "Numerical Rating Scale" (NRS) with ratings from 0 to 9 within four grades (pain-free, mild, moderate, and severe), each patient recorded the pre- and postendodontic pain intensities at 11 time intervals. The PGS, with no assessment/alternation of the data, entered them directly into the trial database http://www.mcrct.ir. The database was inaccessible if the related data for each patient did not timely enter. At the end of study, coded data without the names of patients and treatment groups were extracted and analysed.

2.14. Statistical Analyses. The analysis of data was performed using SPSS software (SPSS 21, SPSS Inc., Chicago, IL, USA). The comparisons were considered significant if $P<0.05$. 
A comparison of baseline demographic data was performed with one-way analysis of variance test (ANOVA) for age and the Pearson chi-squared test $\left(\chi^{2}\right)$ for age categories, sex, marital status, years of schooling, and distribution of treated teeth.

Data for preoperative conditions including preoperative PIs, dental characteristics, preoperative pulp sensibility tests, and presence of apical periodontitis [PDL widening (periapical status was assessed using the periapical index [30]) or positive response to percussion test] were tested using ANOVA, $\chi^{2}$, and Fisher Exact Test (FET).

Data for intraoperative factors, i.e., type of pulp exposure, type of bleeding, irrigants usage for hemostasis, length of treatment, and number of treatment sessions, were analysed using Kruskal Wallis, ANOVA, $\chi^{2}$, and FET.

Data for postoperative factors, including postoperative pulp sensibility tests and analgesic intake, were tested using independent $t$-test, ANOVA, $\chi^{2}$, and FET.

The postoperative pain intensity, trend, distribution of severity, and survival in the study arms were compared using one-way/repeated measure ANOVA, ANCOVA, Kruskal Wallis, and Kaplan-Meier (log-rank) test.

\section{Results}

Five-hundred fifty participants that met the inclusion criteria agreed to be randomised in the study arms: 188 (34\%) in PMTA, 194 (35\%) in PCEM, and 168 (31\%) in RCT (Figure 1). They were recruited from seven academic endodontic departments in seven dental schools, located in five states of Iran. Patients' recruitment started from March 2017 and ended in March 2018. All participants finalised the follow-up for 7 days. Participant demographics, i.e., age, age categories, gender, marital status, and level of educational, were normally distributed and were homogeneous $(P>0.05)$ (Table 1).

Baseline characteristics and preoperative conditions, i.e., preoperative PI, distribution of treated teeth and their characteristics (presence or absence of occlusal contact/ occlusal attrition/coronal restoration), the results of clinical/ radiographic examinations (sensibility testing), and final clinical diagnosis, in all experimental arms, were similar $(P>0.05)$ (Table 2).

Except number of treatment visits $(P<0.001)$ and the treatment length of endodontic procedures $(P<0.001)$, all intraoperative conditions, i.e., type of pulpal exposure, nature of bleeding, achieving hemostasis, treatment length of restorative procedures, and number of treatment sessions, were similar in the three study arms $(P>0.05)$ (Table 3$)$.

Postoperative conditions, i.e., response to sensibility testing (only in pulpotomy arms), percussion tests, and analgesic intake, were comparable in all study arms $(P>0.05)$ (Table 4).

Repeated measure ANOVA revealed that whilst PI changes, during post-operative 7 days, were statistically significant $(P<0.001)$, the trend of PI scores amongst three study arms was similar during the study (interaction effect, $P=0.821)$. There was no difference between arms for the quantity of pain relief $(P=0.947)$ (Figure 2$)$. In addition, the scores of preoperative PI were correlated with experienced postoperative sum PIs $(P=0.002)$.

In terms of grouping pain severities (i.e., pain-free status, mild, moderate, and severe pain) in different postoperative time intervals, Kruskal-Wallis test revealed that there were no significant differences between the study arms $(P=0.496-0.942)$. In addition, the distribution of pain severities was comparable between the arms $(P=0.056-0.993)$ (Table 5). The mean and median time to pain-free status in the three study arms were from 54 to $58 \mathrm{~h}$ and 18 to $24 \mathrm{~h}$, respectively, with no significant difference (Table 6, Figure 3).

Repeated-measures ANOVA with postoperative PIs during the study as within-subjects factors, sex, marital status, age groups, and level of education as between-subjects factors showed that there were no significant effects $(P=0.626,0.197,0.834$, and 0.386 , resp.). When dental characteristics were set as between-subjects factors, the test revealed that there were no statistical differences for the presence or absence of occlusal contact, occlusal attrition, and coronal restorations ( $P=0.702,0.393$, and 0.059 , resp.). When presence or absence of clinical apical periodontitis (positive response to percussion test), detection of PDL widening/lesion, and diagnosis of irreversible pulpitis were set as between-subjects factor, the test revealed that cases with apical periodontitis or PDL widening/lesion significantly suffered more pain $(P=0.035$ and 0.023 , resp.) (Figure 4). However, there was no such pattern for irreversible pulpitis cases $(P=0.782)$. In addition, severity of hemorrhage after pulp exposure, as well as hemostasis achievement after application of $\mathrm{CHX}$, had no influence on postoperative PIs ( $P=0.452$ and 0.438 , resp.). Finally, other factors/conditions had no significant effect on postoperative PI in the study arms $(P>0.05)$.

\section{Discussion}

Pulpal pain, as a major component of oral health-related quality of life, is often the stimulus for patients to seek endodontic care [31]. In addition, postendodontic pain relief is an important concern when evaluating endodontic treatment alternatives, i.e., VPTs [24]. The present randomised clinical trial studied the pain relief effect of PMTA/ PCEM as an alternative treatment modality in comparison with RCT (with rotary instrumentation) as a standard protocol, in the management of cariously exposed dental pulp in symptomatic/asymptomatic mature molars. The obtained results revealed that, as well as RCT, postendodontic pain relief of new biological treatments, i.e., PMTA/PCEM, was highly effective.

Bacterial invasion is often the cause for pulpal inflammation, which is considered as the cause of toothache. Therefore, the pulpal pain should be reduced if (i) the irritating factors are eliminated, (ii) the inflamed pulp is removed, and (iii) the surgical wound is protected by antibacterial BECs [32]. Previous research showed that coronal pulpotomy, using MTA or CEM cement, effectively controlled the preoperative pain in cases with irreversible pulpitis [26]. 




FIgURE 1: CONSORT flow diagram of participants through each stage of randomized clinical trial.

TABLE 1: Comparison of patient demographics in the three study arms.

\begin{tabular}{|c|c|c|c|c|c|}
\hline Demographics & $\operatorname{RCT}(n=168)$ & PMTA $(n=188)$ & PCEM $(n=194)$ & Test & $P$ value \\
\hline Age (mean years $\pm \mathrm{SE})$ & $29.59 \pm 0.83$ & $28.89 \pm 0.77$ & $29.77 \pm 0.75$ & ANOVA & 0.70 \\
\hline $\begin{array}{c}\text { Age category, } N(\%) \\
10 \leq \text { age } \leq 20 \\
20<\text { age } \leq 30 \\
30<\text { age } \leq 40 \\
40<\text { age } \leq 50 \\
50<\text { age } \leq 61\end{array}$ & $\begin{array}{c}33(19.6) \\
53(31.5) \\
54(32.1) \\
20(11.9) \\
8(4.8)\end{array}$ & $\begin{aligned} 40 & (21.3) \\
66 & (35.1) \\
52 & (27.7) \\
25 & (13.3) \\
5 & (2.7)\end{aligned}$ & $\begin{aligned} 33 & (17.0) \\
72 & (37.1) \\
57 & (29.4) \\
25 & (12.9) \\
7 & (3.6)\end{aligned}$ & $\chi^{2}$ & 0.894 \\
\hline $\begin{array}{l}\text { Sex, } N(\%) \\
\quad \text { Male } \\
\text { Female } \\
\end{array}$ & $\begin{array}{c}55(32.7) \\
113(67.3) \\
\end{array}$ & $\begin{array}{c}76(40.4) \\
112(59.6) \\
\end{array}$ & $\begin{array}{c}63(32.5) \\
131(67.5) \\
\end{array}$ & $\chi^{2}$ & 0.190 \\
\hline $\begin{array}{l}\text { Marital status, } N(\%) \\
\text { Single } \\
\text { Married } \\
\end{array}$ & $\begin{array}{c}68(40.5) \\
100(59.5) \\
\end{array}$ & $\begin{array}{c}86(45.7) \\
102(54.3) \\
\end{array}$ & $\begin{array}{c}80(41.2) \\
114(58.8) \\
\end{array}$ & $\chi^{2}$ & 0.544 \\
\hline $\begin{array}{l}\text { Educational level, } N(\% \\
\text { Noneducated } \\
<12 \text { years } \\
=12 \text { years (diploma) } \\
\text { Associate of science } \\
\text { Bachelor of science } \\
\text { Master of science } \\
\text { Doctorate }\end{array}$ & $\begin{aligned} 2 & (1.2) \\
59 & (35.1) \\
50 & (29.8) \\
12 & (7.1) \\
36 & (21.4) \\
5 & (3.0) \\
4 & (2.4)\end{aligned}$ & $\begin{aligned} 2 & (1.1) \\
61 & (32.4) \\
61 & (32.4) \\
13 & (6.9) \\
35 & (18.6) \\
8 & (4.3) \\
8 & (4.3)\end{aligned}$ & $\begin{array}{c}6(3.1) \\
66(34.0) \\
57(29.4) \\
14(7.2) \\
34(17.5) \\
13(6.7) \\
4(2.1)\end{array}$ & $\chi^{2}$ & 0.739 \\
\hline
\end{tabular}

In all studied arms, mean preoperative PI scores were comparable (approximately 4 on the scale of 0-9 in NRS), which were similarly decreased to approximately 1 and 0.5 , one and seven days after treatments, respectively. In addition, the median time to pain-free status for all patients was
18-24 h. These results indicated that pulpotomy with BECs could be considered as effective as RCT in postendodontic pain relief; and, thus, the null hypothesis was accepted. These findings are supported with those of a systematic review which showed that moderate pretreatment root canal- 
TABLE 2: Baseline characteristics and preoperative conditions in the three study arms.

\begin{tabular}{|c|c|c|c|c|c|}
\hline Preoperative factors & $\operatorname{RCT}(n=168)$ & PMTA $(n=188)$ & $\operatorname{PCEM}(n=194)$ & Test & $P$ value \\
\hline $\begin{array}{l}\text { Pain intensity, 0-9 scale (mean } \pm \text { SE) } \\
95 \% \text { Confidence Interval (CI) for Mean }\end{array}$ & $\begin{array}{c}3.95 \pm 0.21 \\
3.54-4.37\end{array}$ & $\begin{array}{c}3.95 \pm 0.20 \\
3.56-4.35\end{array}$ & $\begin{array}{l}3.94 \pm 0.19 \\
3.55-4.33\end{array}$ & ANOVA & 0.998 \\
\hline $\begin{array}{l}\text { Distribution of teeth, } N(\%) \\
\text { Maxilla } \\
\text { Mandible } \\
\end{array}$ & $\begin{array}{l}76(45.2) \\
92(54.8) \\
\end{array}$ & $\begin{array}{c}87(46.3) \\
101(53.7) \\
\end{array}$ & $\begin{array}{c}88(45.4) \\
106(54.6) \\
\end{array}$ & $\chi^{2}$ & 0.976 \\
\hline $\begin{array}{l}\text { First molar } \\
\text { Second molar } \\
\text { Third molar }\end{array}$ & $\begin{aligned} & 95(56.5) \\
& 71(42.3) \\
& 2(1.2) \\
&\end{aligned}$ & $\begin{array}{c}105(55.9) \\
80(42.6) \\
3(1.6) \\
\end{array}$ & $\begin{aligned} & 107(55.2) \\
& 81(41.8) \\
& 6(3.1) \\
&\end{aligned}$ & Fisher & 0.806 \\
\hline $\begin{array}{l}\text { Characteristics of teeth, } N(\%) \\
\text { With occlusal contact } \\
\text { Without occlusal attrition } \\
\text { Presence of coronal restoration }\end{array}$ & $\begin{array}{c}155(92.3) \\
161(95.8) \\
41(24.4) \\
\end{array}$ & $\begin{array}{l}168(89.4) \\
181(96.3) \\
39(20.7) \\
\end{array}$ & $\begin{array}{c}175(90.2) \\
183(94.3) \\
44(22.7) \\
\end{array}$ & $\begin{array}{c}\chi^{2} \\
\text { Fisher } \\
\chi^{2} \\
\end{array}$ & $\begin{array}{l}0.602 \\
0.881 \\
0.714 \\
\end{array}$ \\
\hline $\begin{array}{l}\text { Electric pulp testing (mean } \pm \text { SE) } \\
N(\%)\end{array}$ & $\begin{array}{l}7.52 \pm 0.70 \\
166(98.8)\end{array}$ & $\begin{array}{l}6.64 \pm 0.53 \\
188(100.0)\end{array}$ & $\begin{array}{l}7.36 \pm 0.63 \\
192(99.0)\end{array}$ & $\begin{array}{l}\text { ANOVA } \\
\text { Fisher }\end{array}$ & $\begin{array}{l}0.570 \\
0.468 \\
\end{array}$ \\
\hline Cold testing (normal response), $N(\%)$ & $124(73.8)$ & $132(70.2)$ & $142(73.2)$ & Fisher & 0.388 \\
\hline Widening of PDL, $N(\%)$ & $11(6.5)$ & $13(6.9)$ & $12(6.2)$ & $\chi^{2}$ & 0.969 \\
\hline $\begin{array}{l}\text { Symptomatic irreversible pulpitis, } N(\%) \\
\text { Symptomatic apical periodontitis, } N(\%)\end{array}$ & $\begin{array}{l}37(22.0) \\
23(13.7)\end{array}$ & $\begin{array}{l}49(26.6) \\
23(12.2)\end{array}$ & $\begin{array}{l}45(23.2) \\
20(10.4)\end{array}$ & $\begin{array}{c}\text { Fisher } \\
\chi^{2}\end{array}$ & $\begin{array}{l}0.388 \\
0.662\end{array}$ \\
\hline
\end{tabular}

TABLE 3: Comparison of intraoperative conditions in the three study arms.

\begin{tabular}{|c|c|c|c|c|c|}
\hline Intraoperative factors & $\operatorname{RCT}(n=168)$ & PMTA $(n=188)$ & $\operatorname{PCEM}(n=194)$ & Test & $P$ value \\
\hline $\begin{array}{l}\text { Bleeding nature, } N(\%) \\
\text { Not recorded } \\
\text { Oozing } \\
\text { Normal } \\
\text { Profound } \\
\end{array}$ & $\begin{array}{l}31(18.5) \\
39(23.2) \\
82(48.8) \\
16(9.5) \\
\end{array}$ & $\begin{array}{l}30(16.0) \\
64(12.0) \\
73(38.8) \\
21(11.2) \\
\end{array}$ & $\begin{array}{l}26(13.4) \\
55(28.4) \\
81(41.8) \\
32(16.4) \\
\end{array}$ & $\begin{array}{c}\text { Kruskal } \\
\text { Wallis }\end{array}$ & 0.105 \\
\hline $\begin{array}{l}\text { Hemostasis: not achieved, } N(\%) \\
\text { Using chlorhexidine }(5 \mathrm{~min}) \\
\text { Using sodium hypochlorite }(30 \mathrm{sec}) \\
\end{array}$ & $\begin{array}{l}\text { NA } \\
\text { NA } \\
\end{array}$ & $\begin{array}{c}83(44.1) \\
3 *(1.6) \\
\end{array}$ & $\begin{array}{c}91(55.9) \\
5^{*}(2.6) \\
\end{array}$ & $\begin{array}{c}\chi^{2} \\
\text { Fisher }\end{array}$ & $\begin{array}{l}0.493 \\
0.723 \\
\end{array}$ \\
\hline $\begin{array}{l}\text { Treatment length, minutes (mean } \pm \mathrm{SE} \text { ) } \\
\text { Endodontic procedure } \\
\text { 95\% Confidence Interval (CI) for Mean } \\
\text { Restorative procedure } \\
\text { 95\% Confidence Interval (CI) for Mean }\end{array}$ & $\begin{array}{l}69.73 \pm 2.60 \\
64.59-74.86 \\
39.00 \pm 1.29 \\
36.43-4157 \\
\end{array}$ & $\begin{array}{l}35.37 \pm 1.27 \\
32.87-37.88 \\
42.17 \pm 1.80 \\
38.61-45.74 \\
\end{array}$ & $\begin{array}{l}33.62 \pm 1.19 \\
31.26-35.97 \\
41.59 \pm 1.66 \\
38.30-44.87 \\
\end{array}$ & $\begin{array}{l}\text { ANOVA } \\
\text { ANOVA }\end{array}$ & $\begin{array}{l}<0.001 \\
0.356\end{array}$ \\
\hline Two-visit treatment, $N(\%)$ & $49(29.1)$ & $1(0.05)$ & $1(0.05)$ & $x^{2}$ & $<0.001$ \\
\hline
\end{tabular}

*All the teeth have achieved hemostasis after $10 \mathrm{~min}$ application of $\mathrm{NaOCl}$.

TABLE 4: Comparison of postoperative conditions in the three study arms.

\begin{tabular}{|c|c|c|c|c|c|}
\hline Postoperative factors & RCT $(n=168)$ & PMTA $(n=188)$ & PCEM $(n=194)$ & Test & $P$ value \\
\hline $\begin{array}{l}\text { Cold test, } N(\%) \\
\text { Negative response } \\
\text { Positive response } \\
\end{array}$ & $\begin{array}{l}\text { NA } \\
\text { NA }\end{array}$ & $\begin{array}{c}139(73.9) \\
49(26.1) \\
\end{array}$ & $\begin{array}{c}151(77.8) \\
43(22.2)\end{array}$ & $\chi^{2}$ & 0.373 \\
\hline $\begin{array}{l}\text { Electric pulp test, positive response, } N(\%) \\
\text { Mean } \pm \text { SE } \\
95 \% \text { Confidence Interval (CI) for Mean } \\
\end{array}$ & $\begin{array}{l}\text { NA } \\
\text { NA } \\
\text { NA }\end{array}$ & $\begin{array}{c}99(52.7) \\
4.91 \pm 0.62 \\
3.70-6.13 \\
\end{array}$ & $\begin{array}{c}93(47.9) \\
5.09 \pm 0.72 \\
3.65-6.53 \\
\end{array}$ & $\chi^{2} t$-test & $\begin{array}{l}0.356 \\
0.857\end{array}$ \\
\hline Positive percussion test, $N(\%)$ & $10(6.0)$ & $11(5.9)$ & $15(7.7)$ & $\chi^{2}$ & 0.712 \\
\hline $\begin{array}{l}\text { Analgesic intake } \\
\text { Mean number of tablets/persons } \pm \text { SD } \\
\text { 95\% Confidence Interval (CI) for Mean } \\
\text { Analgesics used, number of people (\%) }\end{array}$ & $\begin{array}{l}1.51 \pm 0.13 \\
1.24-1.77 \\
108(64.3) \\
\end{array}$ & $\begin{array}{c}1.50 \pm 0.12 \\
1.26-1.74 \\
117(62.2) \\
\end{array}$ & $\begin{array}{l}1.61 \pm 0.14 \\
1.32-1.89 \\
128(66.0) \\
\end{array}$ & $\begin{array}{l}\text { ANOVA } \\
\chi^{2}\end{array}$ & $\begin{array}{l}0.809 \\
0.747 \\
\end{array}$ \\
\hline $\begin{array}{l}\text { Drug, } N(\%) \\
\text { Acetaminophen (w/o codeine) } \\
\text { Gelofen } \\
\text { Ibuprofen } \\
\text { Others }\end{array}$ & $\begin{aligned} 21 & (19.4) \\
42 & (38.9) \\
37 & (34.3) \\
8 & (7.4)\end{aligned}$ & $\begin{aligned} 31 & (26.5) \\
55 & (47.0) \\
31 & (26.5) \\
0 & (0.0)\end{aligned}$ & $\begin{array}{c}29(22.7) \\
59(46.1) \\
34(26.6) \\
6(4.7)\end{array}$ & Fisher & 0.066 \\
\hline
\end{tabular}




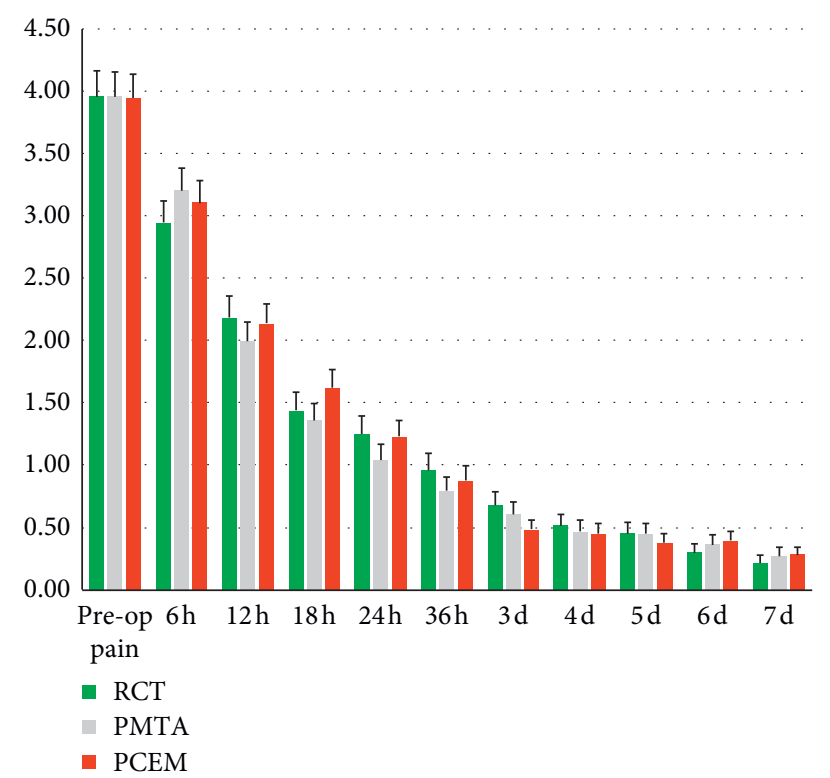

FIgure 2: Pain intensities during the study in the RCT, PMTA, and PCEM arms.

Table 5: Frequency distribution of pain severities $[N(\%)]$ during 7 postoperative days in the three study arms.

\begin{tabular}{|c|c|c|c|c|c|c|c|}
\hline \multirow{2}{*}{ Day } & \multirow{2}{*}{ Arm } & \multicolumn{4}{|c|}{ PI category } & \multirow{2}{*}{ Reporting pain (\%) } & \multirow{2}{*}{$P$ value } \\
\hline & & Pain-free & Mild & Moderate & Severe & & \\
\hline \multirow{3}{*}{ Baseline } & RCT $^{*}$ & $27(16.1)$ & $46(27.4)$ & $58(34.5)$ & $37(22.0)$ & 83.9 & \multirow{3}{*}{0.998} \\
\hline & PMTA & $30(16.0)$ & $53(28.2)$ & $67(35.6)$ & $38(20.2)$ & 84.0 & \\
\hline & PCEM $^{\dagger}$ & $28(14.4)$ & $56(28.9)$ & $68(35.1)$ & $42(21.6)$ & 85.6 & \\
\hline \multirow{3}{*}{$6 \mathrm{~h}$} & RCT & $32(19.0)$ & $77(45.8)$ & $46(27.4)$ & $13(7.7)$ & 81.0 & \multirow{3}{*}{0.337} \\
\hline & PMTA & $33(17.6)$ & $73(38.8)$ & $68(36.2)$ & $14(7.4)$ & 82.4 & \\
\hline & PCEM & $43(22.2)$ & $72(37.1)$ & $58(29.9)$ & $21(10.8)$ & 77.8 & \\
\hline \multirow{3}{*}{$12 \mathrm{~h}$} & RCT & $60(35.7)$ & $61(36.3)$ & $38(22.6)$ & $9(5.4)$ & 64.3 & \multirow{3}{*}{0.585} \\
\hline & PMTA & $67(35.6)$ & $78(41.5)$ & $39(20.7)$ & $4(2.1)$ & 64.4 & \\
\hline & PCEM & $66(34.0)$ & $80(41.2)$ & $37(19.1)$ & $11(5.7)$ & 66.0 & \\
\hline \multirow{3}{*}{$18 \mathrm{~h}$} & $\mathrm{RCT}$ & $86(51.2)$ & $59(35.1)$ & $18(10.7)$ & $5(3.0)$ & 48.8 & \multirow{3}{*}{0.593} \\
\hline & PMTA & $92(48.9)$ & $73(38.8)$ & $20(10.6)$ & $3(1.6)$ & 51.1 & \\
\hline & PCEM & $91(46.9)$ & $70(36.1)$ & $23(11.9)$ & $10(5.2)$ & 53.1 & \\
\hline \multirow{3}{*}{$24 \mathrm{~h}$} & RCT & $100(59.5)$ & $46(27.4)$ & $18(10.7)$ & $4(2.4)$ & 40.5 & \multirow{3}{*}{0.918} \\
\hline & PMTA & $115(61.2)$ & $53(28.2)$ & $17(9.0)$ & $3(1.6)$ & 38.8 & \\
\hline & PCEM & $109(56.2)$ & $60(30.9)$ & $19(9.8)$ & $6(3.1)$ & 43.8 & \\
\hline \multirow{3}{*}{$36 \mathrm{~h}$} & RCT & $111(66.1)$ & $38(22.6)$ & $16(9.5)$ & $3(1.8)$ & 33.9 & \multirow{3}{*}{0.056} \\
\hline & PMTA & $131(69.7)$ & $41(21.8)$ & $15(8.0)$ & $1(0.5)$ & 30.3 & \\
\hline & PCEM & $126(64.9)$ & $56(28.9)$ & $6(3.1)$ & $6(3.1)$ & 35.1 & \\
\hline \multirow{3}{*}{$3 \mathrm{~d}$} & RCT & $125(74.4)$ & $31(18.5)$ & $12(7.1)$ & $0(0.0)$ & 25.6 & \multirow{3}{*}{0.148} \\
\hline & PMTA & $143(76.1)$ & 35 (18.6) & $7(3.7)$ & $3(1.6)$ & 23.9 & \\
\hline & PCEM & $148(76.3)$ & $41(21.1)$ & $4(2.1)$ & $1(0.5)$ & 23.7 & \\
\hline \multirow{3}{*}{$4 \mathrm{~d}$} & RCT & $132(78.6)$ & $31(18.5)$ & $5(3.0)$ & $0(0.0)$ & 21.4 & \multirow{3}{*}{0.508} \\
\hline & PMTA & $155(82.4)$ & $24(12.8)$ & $8(4.3)$ & $1(0.5)$ & 17.6 & \\
\hline & PCEM & $158(81.4)$ & $30(15.5)$ & $4(2.1)$ & $2(1.0)$ & 18.6 & \\
\hline \multirow{3}{*}{$5 \mathrm{~d}$} & RCT & $137(81.5)$ & $25(14.9)$ & $5(3.0)$ & $1(0.6)$ & 18.5 & \multirow{3}{*}{0.993} \\
\hline & PMTA & $155(82.4)$ & $26(13.8)$ & $6(3.2)$ & $1(0.5)$ & 17.6 & \\
\hline & PCEM & $164(84.5)$ & $23(11.9)$ & $6(3.1)$ & $1(0.5)$ & 15.5 & \\
\hline \multirow{3}{*}{$6 \mathrm{~d}$} & RCT & $143(81.5)$ & $23(13.7)$ & $1(0.6)$ & $1(0.6)$ & 18.5 & \multirow{3}{*}{0.719} \\
\hline & PMTA & $162(86.2)$ & $19(10.1)$ & $5(2.7)$ & $2(1.1)$ & 13.8 & \\
\hline & PCEM & $163(84.0)$ & $24(12.4)$ & $5(2.6)$ & $2(1.0)$ & 16.0 & \\
\hline \multirow{3}{*}{$7 d$} & RCT & $147(87.5)$ & $19(11.3)$ & $1(0.6)$ & $1(0.6)$ & 12.5 & \multirow{3}{*}{0.834} \\
\hline & PMTA & $166(88.3)$ & $18(9.6)$ & $4(2.1)$ & $0(0.0)$ & 11.7 & \\
\hline & PCEM & $169(87.1)$ & $21(10.8)$ & $3(1.5)$ & $1(0.5)$ & 12.9 & \\
\hline
\end{tabular}


TABle 6: Mean and median time (hrs) to pain-free status in the study arms.

\begin{tabular}{|c|c|c|c|c|c|c|}
\hline Groups & Mean \pm SE (hrs) & $95 \%$ CI for mean & Median \pm SE (hrs) & 95\% CI for median & Test & $P$ value \\
\hline RCT & $54.54 \pm 4.58$ & $45.56-63.51$ & $18.0 \pm 1.89$ & $14.28-21.72$ & \multirow{3}{*}{ Log rank } & \multirow{3}{*}{0.746} \\
\hline PMTA & $55.57 \pm 4.26$ & $47.22-63.93$ & $24.0 \pm 1.94$ & $20.19-27.81$ & & \\
\hline PCEM & $58.71 \pm 4.23$ & $50.42-67.00$ & $24.0 \pm 3.29$ & $17.54-30.46$ & & \\
\hline
\end{tabular}

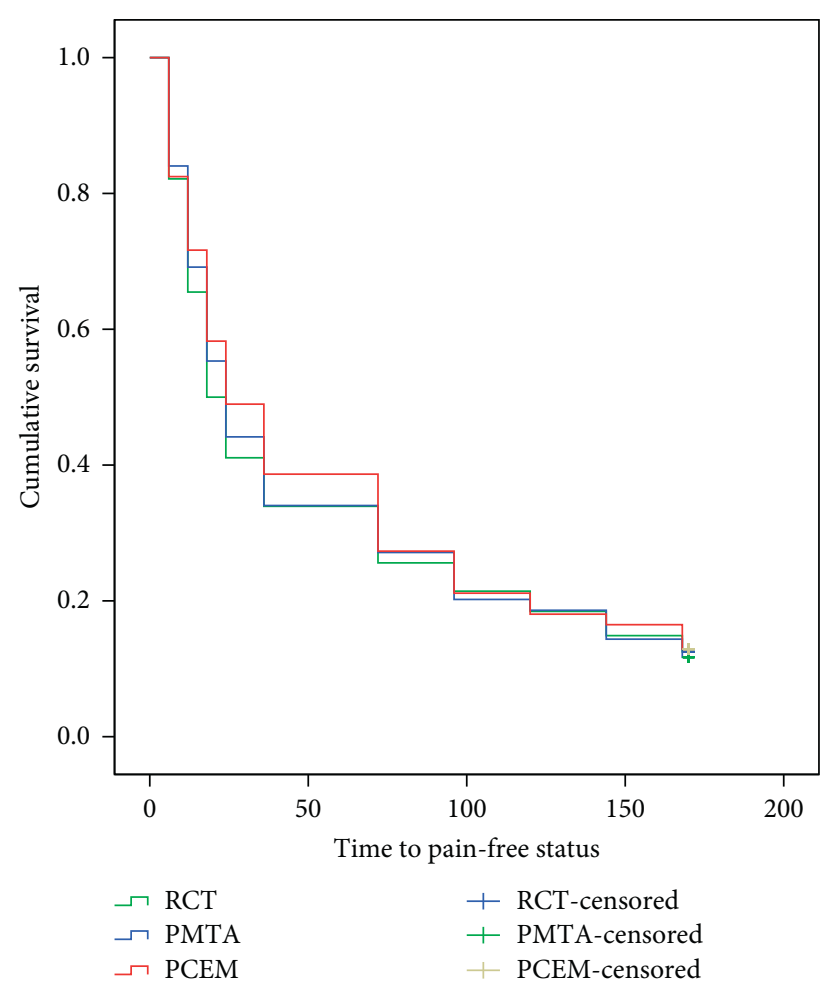

FIgURE 3: Time to pain-free status in the three study arms.

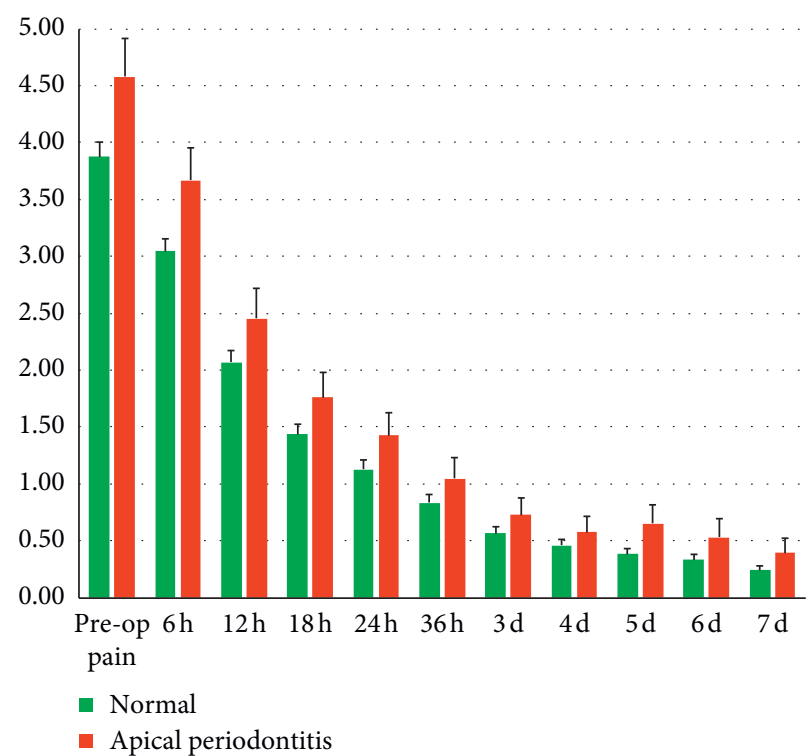

(a)

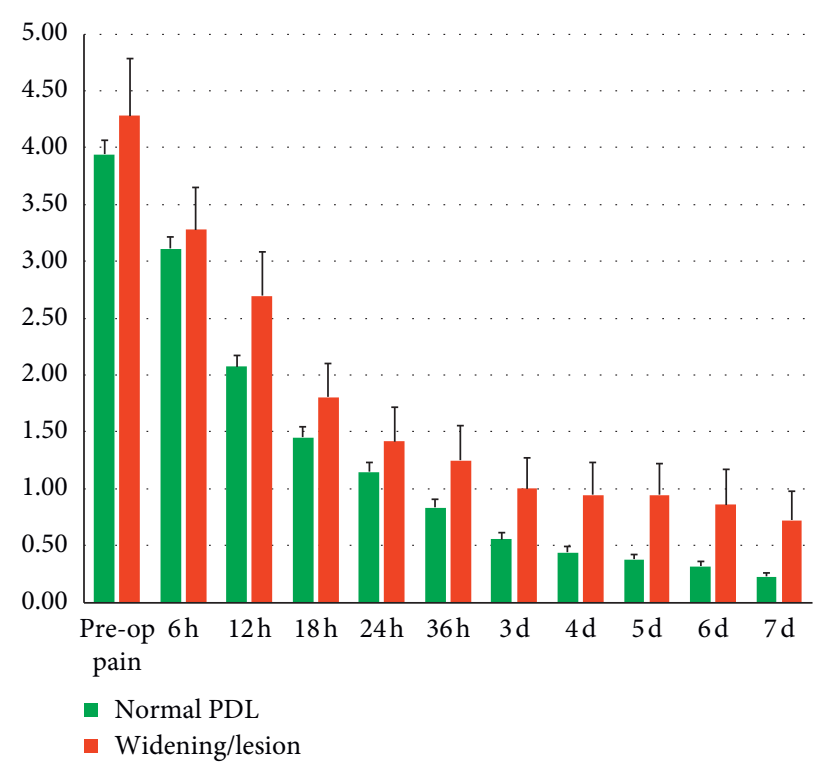

(b)

FIGURE 4: Pain intensity changes in presence or absence of (a) apical periodontitis or (b) PDL widening/lesion. 
associated pain severity dropped significantly within 1 day after treatment and continued to be lower to minimal levels in 7 days [3].

In the present trial, patients with symptomatic apical periodontitis or detected PDL widening/lesion experienced more postoperative pain. In addition, the preoperative PIs were significantly correlated with postoperative PIs. Amongst several predictive factors for postendodontic pain, including patients' age/gender/level of education/marital status, tooth type/location, pulp/periapical status, types of intracanal dressings, systemic analgesic/corticosteroid/antibiotics intake, type of anaesthetics, number of treatment sessions, and different treatment procedures, the presence of preoperative pain is a major predictor of postoperative pain after endodontic treatments [7, 33, 34], which supports our obtained results.

Whilst mean baseline PI scores in this trial were classified as mild, approximately $20-22 \%$ of recruited cases reported severe preoperative pain. 24 hours after RCT (using rotary files) or VPTs, such preoperative pain dramatically decreased to roughly $1-3 \%$ of all patients, with no statistically significant difference between the arms. A previous noninferiority clinical trial on irreversible pulpitis demonstrated the effect of PCEM and one-visit RCT on pain reduction; however, when general dentists treated the teeth, pulpotomy arm significantly had faster/more pain relief than RCT using hand instrumentation techniques [24]. Researchers reported that, compared with coronal pulpotomy, emergency pulpectomy resulted in higher incidence of postoperative pain [35]. A probable source for postendodontic pain is periapical tissue contamination and irritation, initiated by endodontic instrumentation [36]; when dentists were trained to replace manual techniques with nickel-titanium rotary instrumentation, the quality of RCT increased [37]. In addition, with shifting the provider from general dentists to endodontists, treatment outcomes in endodontically treated teeth improved [38]. Thus, clinical expertise as well as the type of the employed techniques may explain such differences.

In this trial, in addition to cases with carious pulp exposure, all cases with clinical signs of irreversible pulpitis were included. Based on the results of the cold test, $23.8 \%$ of enrolled patients were diagnosed with symptomatic irreversible pulpitis. However, postoperative pain relief between patients with or without initial diagnosis of symptomatic irreversible pulpitis was similar. It was assumed that irreversible pulpitis is a clinical term, which indicates that the painful vital inflamed pulp is incapable of healing and needs to be treated with RCT [39]. Currently, new understanding of biology regarding dentine-pulp complex clearly shows that human dental pulp, with irreversible pulpitis, has putative stem cells [40]. In this context, presence of inflammation is not an undesirable phenomenon as it is a prerequisite for pulp healing/regeneration like all the other body connective tissues [41]. Numerous clinical trials have shown that teeth, clinically diagnosed with irreversible pulpitis, could be successfully managed by VPTs [29, 42-45]. Currently, the growing body of evidence has established that clinical sign/symptoms of irreversible pulpitis are not a contraindication for VPTs [44, 46, 47]. These attitudes indicate an outdated classification for dental pulp diseases $[10,31,48]$. Furthermore, VPTs can significantly reduce the preoperative pain of irreversible pulpitis cases [24,26]. Based on these new findings and high-level evidence within this field, it seems that the classification of dental pulp diseases, as well as indication of treatment options, needs a major reconsideration.

At the baseline, although approximately $70-73 \%$ of cases, in all study arms, responded to the cold test, almost all cases responded to EPT (98.8-100\%). One week after full coronal pulpotomy, these responses to the cold test and EPT decreased to approximately $22-26 \%$ and $48-52 \%$, respectively. Amputating the coronal dental pulp with rich subodontoblastic plexus of low-threshold myelinated A-delta sensory afferent fibers and replacing it with BEC, which is expected as an insulator, and maintaining the radicular pulp with high-threshold $\mathrm{C}$ sensory nerve endings, which are located far from coronal tooth surfaces [49], may explain the lesser pulp response to each sensibility testing. In addition, histological studies revealed that, two months after coronal pulpotomy with MTA or CEM cement, hard tissue formation took place at canal orifices [12, 50]. This could probably compromise the responses to sensibility testing with the passage of time and, if needed, complex the further endodontic interventions. It should be noted that diagnostic accuracy of these routine clinical sensibility tests might not be valid for the determination of dental pulp condition [31]. In order to obtain accurate diagnosis of dental pulp status, the sensibility tests should be replaced with pulp vitality tests, i.e., pulse oximetry and laser Doppler flowmetry [51]. These diagnostic technologies mainly focus on pulpal blood supply, not the nerve supply.

Inability of paying for dental services while suffering from endodontic pain [52] and fear of root canal treatments are two major concerns for patients [2]. Obtained results showed that whilst the duration for restorative procedures was comparable in all study arms, duration of pulpotomy was much lesser than RCT (33-35 vs. 69 minutes). In addition, although almost all patients in pulpotomy arms received both endodontic and restorative treatments in one session, $29 \%$ of patients, who underwent RCT, were managed in two sessions. In comparison with pulpectomy/RCT, simplicity of VPTs minimised the fear and time needed for the treatment and caused minimisation in treatment cost $[28,53]$. Even though the treatment effect of RCT and pulpotomy produced equivalent postoperative pain reduction, new biotechnology using BECs might be desirable [54], especially for patients and more specifically for people with low socioeconomic status. If the long-term outcomes of this trial reconfirm the present short-term results, the simple and cost-effective VPT biotechnology [55], employing endodontic biomaterials, i.e., MTA or CEM cement, might become more popular.

In this trial, regardless of nature of bleeding, PGSs applied $0.2 \%$ chlorhexidine solution on all amputated pulps for 5 minutes to achieve hemostasis. However, in approximately $44-56 \%$ of cases, bleeding lasted longer than 5 minutes, which were effectively controlled with the application of full 
strength $\mathrm{NaOCl}$ for 30 seconds. In clinical practice, dentists and specifically pedodontists usually shift vital pulp therapy to pulpectomy or even tooth extraction if excessive hemorrhage is evident after pulp amputation or even at the site of pulp exposure [56]. Basically, in response to microbial irritation, blood-vessel vasodilation and subsequent hyperemia, as the signs of inflammation, occur to help pulpal cells/ tissue with better blood supply [57]. Therefore, when effective elimination of etiological factors along with further protection of remaining pulp with antibacterial/biological sealant takes place, such blood overflow may be beneficial in healing process.

Toothache, as the chief complain of patients, can be definitely treated through extraction or RCT [58]. The latter rapidly causes a dramatic reduction in preoperative endodontic pain [3]. However, endodontic treatment outcome studies have not primarily focused on pain relief as the most exasperating factor for the patient but rather concentrated on the radiographic success, which have two pitfalls. First, many apical periodontitis cases without visible radiographic signs (in the two-dimensional dental radiographs) cause underestimation of actual failure rate of endodontic treatments [59]. Second, long-term radiographic evaluation fails to address the issues of primary concern to patients, i.e., pain.

Participants, without being excluded from the study, were permitted to take effective analgesics if needed postoperatively. The number of people who used analgesics, mean number of taken tablets/persons, and selected drugs were comparable in the study arms. The commonly taken analgesics were gelofen, ibuprofen, and acetaminophen, respectively. A recent systematic review revealed that administration of nonsteroidal anti-inflammatory drugs (NSAIDs) and/or paracetamol was effective in the management of postendodontic pain [60].

In this multicenter randomized controlled trial, the calculated sample size with $90 \%$ power was equal to be 449 ; yet 550 patients were enrolled. As the sample size increases, the minimum point of the power function moves toward one [61]. An appropriate large sample size provides a high power for statistically significant evidence for the efficacy. In addition, based on the nature of our trial, each patient was in his/her own control and preoperative pain and postoperative PIs measures (as effect) were collected with the same scale (NRS). Moreover, and to reduce bias, randomisation was carried out immediately before initiation of treatment procedure using an online computer-generated system. Due to appropriate randomisation process and allocation concealment, the patients' demographics, tooth type/location, and pulp/periapical diagnosis were similar and homogeneous in all experimental arms. Furthermore, the effect of variables that may have had probable association with the postendodontic pain relief was analysed. The above-mentioned items enhanced statistical conclusion validity of the trial.

Although the trial was a multicenter study, it ran in a country with single race (white/Caucasian). It has been reported that chronic pain could be associated with race [62]. Therefore, generalization of obtained results to other races probably needs further investigations.
Our study had two limitations. First, the trial had openlabelled design; and, due to the differences between treatment methods and materials, conducting a blinded study was not possible. Second, we did not assess the socioeconomic status of participants, whilst this factor might be associated with dental pain [63]. However, due to large sample size and appropriate randomisation in our trial, it is expected that this variable, such as other patients' demographics, may be evenly distributed in the three study arms.

A reported adverse side effect, after pulpotomy using calcium-silicate materials, was the potential of tooth discolouration [64]. Grey discolouration of the treated tooth was noticeable after seventeen months [65]. Researchers reported that another unpredictable reaction after coronal pulpotomy was deposition of hard tissue inside the root canals, i.e., pulp obliteration in $30 \%$ of treated cases during 62 months [66]. However, our trial in this phase was graded as short-term one and therefore such potential discolouration and pulp obliteration were not assessable.

\section{Conclusion}

In the management of symptomatic/asymptomatic mature permanent molar teeth with cariously exposed pulp, PMTA/ PCEM and RCT demonstrated effective and comparable postoperative reduction of pain.

\section{Data Availability}

The data used to support the findings of this study are available from the corresponding author upon reasonable request.

\section{Conflicts of Interest}

Saeed Asgary is the inventor of CEM cement (Endodontic Filling Material, USA, 7,942,961, 17 May, 2011). All other authors declare that there are no conflicts of interest regarding the publication of this paper.

\section{Authors' Contributions}

Mohammad Jafar Eghbal, Saeed Asgary, Ali Haeri, Arash Shahravan, Mahta Fazlyab, Alireza Akbarzade Baghban, Eshaghali Saberi, Fariborz Moazami, Mehdi Vatanpour, Mohammad Samiei, Ali Kazemi, and Mohammad Ali Mozayeni were responsible for the conception/design of study. Mohammad Jafar Eghbal, Saeed Asgary, Ali Haeri, and Arash Shahravan were responsible for database design. Mehdi Vatanpour*, Leila Moradi Eslami, Delaram Bineshmarvasti, Gelareh Ghobadi, Nafiseh Emami, Negin Omatali, and Hadi Labaf Ghasemi (Azad Tehran Dental School); Arash Shahravan*, Nasir Kheirabadi, Saeid Rahmani, Azadeh Hashemi, Rahim Fereidooni, and Sara Soofiabadi (Kerman Dental School); Ali Kazemi*, Nafiseh Farajian, and Somaye Teimoori (Shahed Dental School); Mohammad Ali Mozayeni*, Nazila Akbarian Rad, Atefeh Gohari, Behnam Rahbani Nobar, Mohammadreza Hosseini, Parviz Shafaq, and Farzaneh Vatandoost (Shahid Beheshti Dental School); Fariborz Moazami*, Mandana Dehghani, 
Parastu Malekzadeh, Vahid Mehrabi, Roya Dehghan, Elham Karami, and Negar Pourhatami (Shiraz Dental School); Mohammad Samiei*, Paria Davoudi, Mostafa Ghodrati, Mehrnush Mohammadi, Alireza Majidi, Atefeh Noghani, and Sepideh Kozegari (Tabriz Dental School); Eshaghali Saberi*, Shima Bijari, Habibollah Ebrahimi, and Mahboobe Ahmadi (Zahedan Dental School); Ali Haeri and Mahta Fazlyab (ICER) were responsible for patients' enrolment, experiments conduct, and data acquisition (*senior team members). Mohammad Jafar Eghbal, Saeed Asgary, Ali Haeri, Arash Shahravan, and Alireza Akbarzade Baghban performed analysis and/or interpretation of data. Mohammad Jafar Eghbal, Saeed Asgary, Ali Haeri, Arash Shahravan, and Alireza Akbarzade Baghban drafted the manuscript. Mehdi Vatanpour, Arash Shahravan, Ali Kazemi, Mohammad Ali Mozayeni, Fariborz Moazami, Mohammad Samiei, Eshaghali Saberi, and Ardavan Parhizkar revised the manuscript critically for important intellectual content. Mohammad Jafar Eghbal, Saeed Asgary, Ali Haeri, Alireza Akbarzade Bagheban, Mehdi Vatanpour, Arash Shahravan, Ali Kazemi, Mohammad Ali Mozayeni, Fariborz Moazami, Mohammad Samiei, Eshaghali Saberi, and Ardavan Parhizkar approved the version of the manuscript to be published.

\section{Acknowledgments}

The authors would like to thank all patients that took part in this randomized clinical trial. Iranian Center for Endodontic Research has managed the project; Research Institute of Dental Sciences and Shahid Beheshti University of Medical Sciences have permitted this project; the trial was approved and supported by the Deputy Minister of Research, Prof. Reza Malakzadeh, Iranian Ministry of Health and Medical Education; and these are greatly acknowledged. The authors also want to thank Azad Tehran, Kerman, Shahed, Shahid Beheshti, Shiraz, Tabriz, and Zahedan Dental Schools that actively participated in this study and all scientific/administrative people involved in the clinical/organisational works.

\section{References}

[1] N. J. Kassebaum, A. G. C. Smith, E. Bernabé et al., "Global, regional, and national prevalence, incidence, and disabilityadjusted life years for oral conditions for 195 countries, 1990-2015: a systematic analysis for the global burden of diseases, injuries, and risk factors," Journal of Dental Research, vol. 96, no. 4, pp. 380-387, 2017.

[2] R. Hamedy, B. Shakiba, S. Fayazi, J. G. Pak, and S. N. White, "Patient-centered endodontic outcomes: a narrative review," Iranian Endodontic Journal, vol. 8, no. 4, pp. 197-204, 2013.

[3] J. G. Pak and S. N. White, "Pain prevalence and severity before, during, and after root canal treatment: a systematic review," Journal of Endodontics, vol. 37, no. 4, pp. 429-438, 2011.

[4] M. F. Silva-Junior, A. C. C. d. Sousa, M. J. Batista, and M. d. L. R. d. Sousa, "Condição de saúde bucal e motivos para extração dentária entre uma população de adultos (20-64 anos)," Ciência \& Saúde Coletiva, vol. 22, no. 8, pp. 2693-2702, 2017.

[5] C. Sathorn, P. Parashos, and H. Messer, "The prevalence of postoperative pain and flare-up in single- and multiple-visit endodontic treatment: a systematic review," International Endodontic Journal, vol. 41, no. 2, pp. 91-99, 2007.

[6] J. M. Genet, P. R. Wesselink, and S. K. T. Velzen, "The incidence of preoperative and postoperative pain in endodontic therapy," International Endodontic Journal, vol. 19, no. 5, pp. 221-229, 1986.

[7] A. Arias, J. C. de la Macorra, J. J. Hidalgo, and M. Azabal, "Predictive models of pain following root canal treatment: a prospective clinical study," International Endodontic Journal, vol. 46, no. 8, pp. 784-793, 2013.

[8] H. Miyashita, H. V. Worthington, A. Qualtrough, and A. Plasschaert, "Pulp management for caries in adults: maintaining pulp vitality," The Cochrane Database of Systematic Reviews, vol. 18, no. 2, Article ID CD004484, 2007.

[9] M. Kearney, P. R. Cooper, A. J. Smith, and H. F. Duncan, "Epigenetic approaches to the treatment of dental pulp inflammation and repair: opportunities and obstacles," Frontiers in Genetics, vol. 9, p. 311, 2018.

[10] W. J. Wolters, H. F. Duncan, P. L. Tomson et al., "Minimally invasive endodontics: a new diagnostic system for assessing pulpitis and subsequent treatment needs," International Endodontic Journal, vol. 50, no. 9, pp. 825-829, 2017.

[11] H. F. Duncan, K. M. Galler, P. L. Tomson et al., "European Society of Endodontology position statement: management of deep caries and the exposed pulp," International Endodontic Journal, vol. 52, no. 7, pp. 923-934, 2019.

[12] M. J. Eghbal, S. Asgary, R. A. Baglue, M. Parirokh, and J. Ghoddusi, "MTA pulpotomy of human permanent molars with irreversible pulpitis," Australian Endodontic Journal, vol. 35 , no. 1 , pp. $4-8,2009$.

[13] L.-H. Chueh and C.-P. Chiang, "Histology of Irreversible pulpitis premolars treated with mineral trioxide aggregate pulpotomy," Operative Dentistry, vol. 35, no. 3, pp. 370-374, 2010.

[14] S. Yazdani, M. P. Jadidfard, B. Tahani, A. Kazemian, O. Dianat, and L. Alim Marvasti, "Health technology assessment of CEM pulpotomy in permanent molars with irreversible pulpitis," Iranian Endodontic Journal, vol. 9, no. 1, pp. 23-29, 2014.

[15] L. Awawdeh, K. Hemaidat, and W. Al-Omari, "Higher maximal occlusal bite force in endodontically treated teeth versus vital contralateral counterparts," Journal of Endodontics, vol. 43, no. 6, pp. 871-875, 2017.

[16] D. E. Witherspoon, "Vital pulp therapy with new materials: new directions and treatment perspectives-permanent teeth," Journal of Endodontics, vol. 34, no. 7, pp. S25-S28, 2008.

[17] S. Asgary, M. J. Eghbal, M. Parirokh, J. Ghoddusi, S. Kheirieh, and F. Brink, "Comparison of mineral trioxide aggregate's composition with portland cements and a new endodontic cement," Journal of Endodontics, vol. 35, no. 2, pp. 243-250, 2009.

[18] H. Razmi, M. Aminsobhani, B. Bolhari, F. Shamshirgar, S. Shahsavan, and A. R. Shamshiri, "Calcium enriched mixture and mineral trioxide aggregate activities against Enterococcus faecalis in presence of dentin," Iranian Endodontic Journal, vol. 8, no. 4, pp. 191-196, 2013.

[19] K. Nazari Moghadam, H. Aghili, A. Rashed Mohassel, S. Zahedpasha, and A. A. Moghadamnia, "A comparative study on sealing ability of mineral trioxide aggregate, calcium enriched cement and bone cement in furcal perforations," Minerva Stomatol, vol. 63, no. 6, pp. 203-210, 2014.

[20] S. Rahimi, H. Mokhtari, S. Shahi et al., "Osseous reaction to implantation of two endodontic cements: mineral trioxide aggregate (MTA) and calcium enriched mixture (CEM)," 
Medicina Oral Patología Oral Y Cirugia Bucal, vol. 17, no. 5, pp. e907-e911, 2012.

[21] A. Nosrat, A. Peimani, and S. Asgary, "A preliminary report on histological outcome of pulpotomy with endodontic biomaterials vs calcium hydroxide," Restorative Dentistry \& Endodontics, vol. 38, no. 4, pp. 227-233, 2013.

[22] M. Samiee, M. J. Eghbal, M. Parirokh, F. M. Abbas, and S. Asgary, "Repair of furcal perforation using a new endodontic cement," Clinical Oral Investigations, vol. 14, no. 6, pp. 653-658, 2010.

[23] M. Parirokh, M. Torabinejad, and P. M. H. Dummer, "Mineral trioxide aggregate and other bioactive endodontic cements: an updated overview-part I: vital pulp therapy," International Endodontic Journal, vol. 51, no. 2, pp. 177-205, 2018.

[24] S. Asgary and M. J. Eghbal, "The effect of pulpotomy using a calcium-enriched mixture cement versus one-visit root canal therapy on postoperative pain relief in irreversible pulpitis: a randomized clinical trial," Odontology, vol. 98, no. 2, pp. 126-133, 2010.

[25] M. Galani, S. Tewari, P. Sangwan, S. Mittal, V. Kumar, and J. Duhan, "Comparative evaluation of postoperative pain and success rate after pulpotomy and root canal treatment in cariously exposed mature permanent molars: a randomized controlled trial," Journal of Endodontics, vol. 43, no. 12, pp. 1953-1962, 2017.

[26] S. Asgary and M. J. Eghbal, "Treatment outcomes of pulpotomy in permanent molars with irreversible pulpitis using biomaterials: a multi-center randomized controlled trial," Acta Odontologica Scandinavica, vol. 71, no. 1, pp. 130-136, 2013.

[27] C. Keskin, O. Sivas Yilmaz, U. Inan, and O. Ozdemir, "Postoperative pain after glide path preparation using manual, reciprocating and continuous rotary instruments: a randomized clinical trial," International Endodontic Journal, vol. 52, 2019.

[28] S. Asgary, M. J. Eghbal, and J. Ghoddusi, “Two-year results of vital pulp therapy in permanent molars with irreversible pulpitis: an ongoing multicenter randomized clinical trial," Clinical Oral Investigations, vol. 18, no. 2, pp. 635-641, 2014.

[29] S. Asgary, M. J. Eghbal, and A. A. Bagheban, "Long-term outcomes of pulpotomy in permanent teeth with irreversible pulpitis: a multi-center randomized controlled trial," American Journal of Dentistry, vol. 30, no. 3, pp. 151-155, 2017.

[30] D. Orstavik, K. Kerekes, and H. M. Eriksen, "The periapical index: a scoring system for radiographic assessment of apical periodontitis," Dental Traumatology, vol. 2, no. 1, pp. 20-34, 1986.

[31] I. A. Mejàre, S. Axelsson, T. Davidson et al., "Diagnosis of the condition of the dental pulp: a systematic review," International Endodontic Journal, vol. 45, no. 7, pp. 597-613, 2012.

[32] S. Asgary and M. Ahmadyar, "W'Vital pulp therapy using calcium-enriched mixture: an evidence-based review," Journal of Conservative Dentistry, vol. 16, no. 2, pp. 92-98, 2013.

[33] A. S. Law, D. R. Nixdorf, A. M. Aguirre et al., "Predicting severe pain after root canal therapy in the National Dental PBRN," Journal of Dental Research, vol. 94, no. 3, pp. 37S-43S, 2015.

[34] A. Alí, J. G. Olivieri, F. Duran-Sindreu, F. Abella, M. Roig, and M. García-Font, "Influence of preoperative pain intensity on postoperative pain after root canal treatment: a prospective clinical study," Journal of Dentistry, vol. 45, pp. 39-42, 2016.

[35] B. R. Oguntebi, E. J. DeSchepper, T. S. Taylor, C. L. White, and F. E. Pink, "Postoperative pain incidence related to the type of emergency treatment of symptomatic pulpitis," Oral Surgery, Oral Medicine, Oral Pathology, vol. 73, no. 4, pp. 479-483, 1992.
[36] J. M. Genet, A. A. M. Hart, P. R. Wesselink, and S. K. Thoden van Velzen, "Preoperative and operative factors associated with pain after the first endodontic visit," International Endodontic Journal, vol. 20, no. 2, pp. 53-64, 1987.

[37] A. Molander, D. Caplan, G. Bergenholtz, and C. Reit, "Improved quality of root fillings provided by general dental practitioners educated in nickel?titanium rotary instrumentation," International Endodontic Journal, vol. 40, no. 4, pp. 254-260, 2007.

[38] K. Ramey, J. Yaccino, and J. Wealleans, "A retrospective, radiographic outcomes assessment of 1960 initial posterior root canal treatments performed by endodontists and dentists," Journal of Endodontics, vol. 43, no. 8, pp. 1250-1254, 2017.

[39] L. Figini, G. Lodi, F. Gorni, and M. Gagliani, "Single versus multiple visits for endodontic treatment of permanent teeth," The Cochrane Database of Systematic Reviews, vol. 17, no. 4, Article ID CD005296, 2007.

[40] Z. Wang, J. Pan, J. T. Wright et al., "Putative stem cells in human dental pulp with irreversible pulpitis: an exploratory study," Journal of Endodontics, vol. 36, no. 5, pp. 820-825, 2010.

[41] M. Goldberg, A. Njeh, and E. Uzunoglu, "Is pulp inflammation a prerequisite for pulp healing and regeneration?" Mediators of Inflammation, vol. 2015, Article ID 347649, 11 pages, 2015.

[42] S. Asgary, M. J. Eghbal, M. Fazlyab, A. A. Baghban, and J. Ghoddusi, "Five-year results of vital pulp therapy in permanent molars with irreversible pulpitis: a non-inferiority multicenter randomized clinical trial," Clinical Oral Investigations, vol. 19, no. 2, pp. 335-341, 2015.

[43] N. A. Taha and S. Z. Abdelkhader, "Outcome of full pulpotomy using Biodentine in adult patients with symptoms indicative of irreversible pulpitis," International Endodontic Journal, vol. 51, no. 8, pp. 819-828, 2018.

[44] N. A. Taha and M. A. Khazali, "Partial pulpotomy in mature permanent teeth with clinical signs indicative of irreversible pulpitis: a randomized clinical trial," Journal of Endodontics, vol. 43, no. 9, pp. 1417-1421, 2017.

[45] N. Uesrichai, A. Nirunsittirat, P. Chuveera, T. Srisuwan, T. Sastraruji, and P. Chompu-Inwai, "Partial pulpotomy with two bioactive cements in permanent teeth of 6- to 18-year-old patients with signs and symptoms indicative of irreversible pulpitis: a noninferiority randomized controlled trial," International Endodontic Journal, vol. 52, 2019.

[46] N. A. Taha and S. Z. Abdulkhader, "Full pulpotomy with biodentine in symptomatic young permanent teeth with carious exposure," Journal of Endodontics, vol. 44, no. 6, pp. 932-937, 2018.

[47] S. Asgary, R. Hassanizadeh, H. Torabzadeh, and M. J. Eghbal, "Treatment outcomes of 4 vital pulp therapies in mature molars," Journal of Endodontics, vol. 44, no. 4, pp. 529-535, 2018.

[48] L. G. Levin, A. S. Law, G. R. Holland, P. V. Abbott, and R. S. Roda, "Identify and define all diagnostic terms for pulpal health and disease states," Journal of Endodontics, vol. 35, no. 12, pp. 1645-1657, 2009.

[49] H. O. Trowbridge, "Review of dental pain-histology and physiology," Journal of Endodontics, vol. 12, no. 10, pp. 445-452, 1986.

[50] S. Asgary and S. Ehsani, "Permanent molar pulpotomy with a new endodontic cement: a case series," Journal of Conservative Dentistry, vol. 12, no. 1, pp. 31-36, 2009.

[51] H. Farid, F. R. Khan, L. Pasha, and M. S. Shinwari, "Are pulp sensibility tests still sensible?" Journal of Ayub Medical College Abbottabad, vol. 27, no. 4, pp. 874-877, 2015. 
[52] J. J. Villalobos-Rodelo, C. E. Medina-Solis, G. Maupome et al., "Dental needs and socioeconomic status associated with utilization of dental services in the presence of dental pain: a case-control study in children," Journal of Orofacial Pain, vol. 24, no. 3, pp. 279-286, 2010.

[53] B. Eren, E. O. Onay, and M. Ungor, "Assessment of alternative emergency treatments for symptomatic irreversible pulpitis: a randomized clinical trial," International Endodontic Journal, vol. 51, no. 3, pp. e227-e237, 2018.

[54] A. Laupacis, D. Feeny, A. S. Detsky, and P. X. Tugwell, "How attractive does a new technology have to be to warrant adoption and utilization? Tentative guidelines for using clinical and economic evaluations," CMAJ, vol. 146, no. 4, pp. 473-481, 1992.

[55] F. Schwendicke and M. Stolpe, "Direct pulp capping after a carious exposure versus root canal treatment: a cost-effectiveness analysis," Journal of Endodontics, vol. 40, no. 11, pp. 1764-1770, 2014.

[56] R. E. McDonald, D. R. Avery, and J. A. Dean, "Treatment of deep caries, vital pulp exposure, and pulpless teeth," McDonald and Avery Dentistry for the Child and Adolescent, vol. 19, pp. 342-365, 2011.

[57] K. J. Tønder, "Vascular reactions in the dental pulp during inflammation," Acta Odontologica Scandinavica, vol. 41, no. 4, pp. 247-256, 1983.

[58] I. B. Bender, "Reversible and irreversible painful pulpitides: diagnosis and treatment," Australian Endodontic Journal, vol. 26, no. 1, pp. 10-14, 2000.

[59] A. Davies, S. Patel, F. Foschi, M. Andiappan, P. J. Mitchell, and F. Mannocci, "The detection of periapical pathoses using digital periapical radiography and cone beam computed tomography in endodontically retreated teeth-part 2: a 1 year post-treatment follow-up," International Endodontic Journal, vol. 49, no. 7, pp. 623-635, 2016.

[60] A. Shirvani, S. Shamszadeh, M. J. Eghbal, and S. Asgary, "The efficacy of non-narcotic analgesics on post-operative endodontic pain: a systematic review and meta-analysis," Journal of Oral Rehabilitation, vol. 44, no. 9, pp. 709-721, 2017.

[61] D. A. Dickey and W. A. Fuller, "Distribution of the estimators for autoregressive time series with a unit root," Journal of the American Statistical Association, vol. 74, no. 366a, pp. 427431, 1979.

[62] M. A. Day and B. E. Thorn, "The relationship of demographic and psychosocial variables to pain-related outcomes in a rural chronic pain population," Pain, vol. 151, no. 2, pp. 467-474, 2010.

[63] A. N. da Silva and M. V. Vettore, "Sense of coherence modifies the association between untreated dental caries and dental pain in low-social status women," Community Dental Health, vol. 33, no. 1, pp. 54-59, 2016.

[64] M. Parirokh and M. Torabinejad, "Mineral trioxide aggregate: a comprehensive literature review-Part III: clinical applications, drawbacks, and mechanism of action," Journal of Endodontics, vol. 36, no. 3, pp. 400-413, 2010.

[65] I. Belobrov and P. Parashos, "Treatment of tooth discoloration after the use of white mineral trioxide aggregate," Journal of Endodontics, vol. 37, no. 7, pp. 1017-1020, 2011.

[66] P. Linsuwanont, K. Wimonsutthikul, U. Pothimoke, and B. Santiwong, "Treatment outcomes of mineral trioxide aggregate pulpotomy in vital permanent teeth with carious pulp exposure: the retrospective study," Journal of Endodontics, vol. 43, no. 2, pp. 225-230, 2017. 